\title{
A TEORIA DAS REPRESENTAÇÕES SOCIAIS NOS ESTUDOS SOBRE REPRESENTAÇÕES DE PROFESSORES
}

\author{
MARIA SUZANA DE STEFANO MENIN \\ Professora titular do Departamento de Educação e Programa de Pós-Graduação \\ em Educação da Universidade Estadual Paulista - Presidente Prudente \\ sumenin@uol.com.br
}

\author{
ALESSANDRA DE MORAIS SHIMIZU \\ Professora assistente do Departamento de Psicologia da \\ Educação da Universidade Estadual Paulista - Marília \\ ashimizu@flash.tv.br
}

\section{CLAUDIA MARIA DE LIMA}

Professora assistente do Departamento de Educação da Universidade Estadual Paulista - São José do Rio Preto, e professora do Programa de Pós-Graduação em Educação da Universidade Estadual Paulista - Presidente Prudente claudiamarialima@uol.com.br

\section{RESUMO}

A pesquisa apresentada analisou 27 teses de doutorado e dissertações de mestrado de programas brasileiros de Pós-Graduação em Educação que usam a teoria de representações sociais para estudar representações de ou sobre professor. Para a realização dessa análise foram investigados, principalmente, aspectos metodológicos relacionados ao uso da TRS, tais como: modo de descrição dos sujeitos da pesquisa e variáveis selecionadas nessa caracterização; descrição do objeto de

Esta investigação contou com a colaboração, para a construção dos critérios de análise e leitura das teses e dissertações, dos seguintes pesquisadores: Alda Judith Alves-Mazzotti, Margot Madeira e Tarso Mazzotti (Universidade Estácio de Sá - Unisa - RJ); Ângela Martins, Clarilza Prado de Sousa, Marialva Tavares (Fundação Carlos Chagas - FCC - SP); Vera Nigro de Souza Placco (Pontifícia Universidade Católica de São Paulo - PUC - SP); Alessandra M. Shimizu, Claudia M. Lima e Maria Suzana S. Menin. Os participantes dessa pesquisa compõem o subgrupo brasileiro do Grupo Internacional Social Representations, Education and Professional Formations, coordenado pelo prof. dr. Mohamed Chaib (Universidade de Jönköping, Suécia). Contamos, também, com a colaboração de Helenice Maia, Lúcia Velloso Maurício (Unisa) e Juliana Zechi (Unesp/Presidente Venceslau) para a análise das dissertações e teses. A pesquisa faz parte das iniciativas do Centro Internacional de Estudos sobre Representações Sociais e Subjetividade-Educação - Ciers-ED -, da FCC, dirigido por Clarilza Prado de Sousa. 
estudo, sua contextualização e justificação como objeto de representação social; procedimentos de coleta de dados, sua adequação e justificação; tratamento dos dados; procedimentos de análise; síntese dos resultados e sua contribuição para a educação, para a formação de professores e para a TRS. Concluiu-se que a TRS é pouco explorada nos trabalhos, embora, de modo geral, eles contribuam para aclarar as representações que professores têm a respeito de vários campos que compõem sua vida profissional.

TEORIA DAS REPRESENTAÇÕES SOCIAIS - REPRESENTAÇÕES SOCIAIS - FORMAÇÃO DO PROFESSOR - TRABALHO

\section{ABSTRACT}

THE SOCIAL REPRESENTATIONS THEORY IN STUDIES OF TEACHER'S REPRESENTATION: ANALYSIS OF BRAZILIAN THESES AND DISSERTATIONS. This study analyzed 27 Ph.D dissertations and master's theses from Brazilian graduate programs in education that use the social representation theory to study representations of or about teachers. For this analysis, principally methodological aspects related to the use of SRT were used, such as: description of the research subjects and the variables selected for this characterization; description of the research object, its contextualization and justification as an object of social representation; procedures adopted for data collection, their suitability and justification; data treatment; analysis procedures; results summary and their contribution towards education, teacher education programs and SRT. It was concluded that SRT has received little attention from researchers, although generally speaking these studies have contributed to clarifying the representations that teachers have about the different fields that constitute their professional life.

SOCIAL REPRESENTATIONS THEORY - SOCIAL REPRESENTATIONS - TEACHERS TRAINING - WORK

Este trabalho surgiu no contexto da conferência proferida por Denise Jodelet, em outubro de 200 I, no Programa de Pós-Graduação em Educação da Faculdade de Ciências e Tecnologia, da Unesp de Presidente Prudente, e de questões que levantamos em estudo anterior sobre pesquisas a respeito da teoria das representações sociais - TRS - e pesquisas sobre educação apresentadas em congressos.

Jodelet, uma das autoras que mais contribuiu para o desenvolvimento dessa teoria, ex-diretora do Laboratório de Psicologia Social de l'École de Hautes Études en Sciences Sociales de Paris, em uma das nossas primeiras reuniões para a formação do Grupo Representações Sociais, Educação e Formação Profissional, em 2004, em Paris, chamou-nos a atenção para a quantidade de pesquisas nesse campo no Brasil, e sobre como seria interessante e oportuno fazer uma análise dos resultados de tantos anos de estudos, verificando como a 
TRS tem contribuído para o campo da formação profissional: o que tem trazido de mais consistente acerca do trabalho, da formação ou das representações do professor sobre os elementos do seu fazer docente.

Na época, acabávamos de concluir nosso estudo sobre 138 trabalhos apresentados em congressos de educação e representação social da Associação Nacional de Pós-Graduação e Pesquisa em Educação - Anped -, das Jornadas Internacionais sobre Representações Sociais - Jirs - e do Grupo de Pesquisa Cultura, Identidade e Representações Sociais - Cirs -, no período de 2000 a 2003 (Menin, Shimizu, 2005), que usavam a TRS para responder às questões na área da educação. Nesse estudo, levantamos questões a respeito da qualidade do uso da TRS em pesquisas brasileiras. Constatamos, como outros autores já haviam feito (Sousa, 2002; Arruda, 2005), que a teoria tem sido extremamente útil para revelar as relações entre conhecimentos práticos e desempenho de papéis e de funções na escola, de um lado, e questões ideológicas, políticas, pedagógicas no campo da educação, de outro. No entanto, identificamos certos problemas metodológicos e outros relacionados à falta de profundidade das investigações, como:

- poucos estudos verificam ancoragens das representações, uma vez que mais descrevem representações do que revelam sua origem;

- são feitas poucas comparações entre conhecimentos do senso comum - as representações - e conhecimentos escolares de cunho mais científico; os estudos são mais descritivos que comparativos ou explicativos;

- em relação ao tipo de análise, os estudos priorizam a descrição e classificação das representações obtidas por meio de questionários e entrevistas em detrimento da sua análise estrutural; faltam pesquisas que explorem a análise de conteúdos e processos cognitivos das representações previstos como possibilidades interessantes da teoria;

- os sujeitos das investigações são frequentemente mal caracterizados, na medida em que não se investigam as ancoragens das representações em fatores relativos à pertinência ou história cultural dos grupos;

- faltam aos estudos perspectivas de análises mais antropológicas e sociológicas que explorem as pertinências e experiências grupais, sociais e culturais das representações; 
- poucas pesquisas investigam transformações das representações sociais, sejam as históricas, decorrentes de fatores culturais ou políticos, sejam aquelas provocadas por situações específicas de treinamento ou formação, limitação que pode ser explicada pela falta de tempo para investigações nos programas de pós-graduação, como sugere Sousa (2002), ou pela falta de tradição de trabalhos longitudinais e pela tendência de realizar pesquisas mais descritivas que explicativas;

- as relações entre representações e práticas são mais inferidas, pensadas como hipóteses e discutidas do que investigadas diretamente;

- poucos estudos analisam a difusão das representações pela mídia, apesar da grande importância dessa fonte de comunicação na construção das representações sociais, como demonstrou Moscovici (1978), publicado originalmente em 1961; os meios de divulgação das representações são mais inferidos que investigados, o que já foi observado por Sousa (2002);

- finalmente, embora a maioria dos trabalhos use métodos muito simples de análise de dados (descrição, classificação, quantificação das representações), alguns avançam na análise de conteúdos graças aos recursos proporcionados pelos softwares disponíveis.

Assim, embora a pesquisa em representações sociais em educação seja um campo dos mais frutíferos no Brasil, como mostra Arruda (2005), a quantidade da produção não é acompanhada obrigatoriamente de profundidade ou rigor metodológico. Pensamos que este é um bom momento para fazer sínteses críticas dessa produção, investigando suas tendências metodológicas e suas principais contribuições em um campo de grande interesse: a formação do professor.

A pesquisa aqui apresentada centra-se na análise de teses e dissertações em educação e representações sociais que têm como objeto de estudos representações de ou sobre o professor. Pretende-se investigar como esses trabalhos se organizam metodologicamente de forma a usar a TRS como referencial teórico e ferramenta de investigação, e que contribuições trazem para a área da educação. 


\section{METODOLOGIA}

\section{As teses e dissertações}

Escolhemos para análise teses de doutorado e dissertações de mestrado defendidas no ano de 2004 em Programas brasileiros de Pós-Graduação em Educação reconhecidos pela Coordenação de Aperfeiçoamento de Pessoal de Nível Superior - Capes. Fizemos primeiramente uma leitura dos resumos das 2.327 teses e dissertações defendidas nesse ano, e localizamos 29 que utilizavam a TRS para o estudo de representações sociais de ou sobre o profissional professor. Desses trabalhos, produzidos em universidades de diversos estados do país, apenas dois não foram encontrados. Os 27 restantes, quatro teses de doutorado e 22 dissertações de mestrado, foram lidos na íntegra e analisados segundo critérios estabelecidos pelo grupo de pesquisadores participantes dessa investigação.

\section{Critérios de análise}

Os critérios estabelecidos para a análise das teses e dissertações referiram-se à:

- escolha do objeto de representação a ser investigado;

- pertinência do objeto de investigação ao conjunto de sujeitos;

- escolha e descrição dos sujeitos da pesquisa;

- pertinência da revisão bibliográfica, verificando como os autores são utilizados para a exposição dos conceitos da teoria;

- descrição e pertinência dos procedimentos de coleta, do tratamento dos dados;

- exposição e coerência dos procedimentos das análises;

- indicação das principais contribuições do estudo para a TRS e para a educação.

\section{RESULTADOS}

Tema dos trabalhos e identificação dos objetos das pesquisas 
Entre os temas priorizados nas 27 teses e dissertações' encontram-se:

- representações do "ser professor" ou de sua "identidade" (Sixel da Silva; Costa e Silva), representações sobre o curso de Pedagogia e a formação docente (Pereira), representações sobre a função do professor e da instituição de educação infantil (Assis; David);

- representações sociais de profissão e profissionalização docente produzidas por professores que atuam ensino fundamental e que integram um determinado curso de formação (Marujo);

- representações dos docentes sobre saberes considerados necessários à profissão (Brito);

- representações sobre avaliação (Cunha);

- representações sociais do ingresso na formação em serviço, da repercussão do processo formativo sobre a mudança da prática docente (Costa) e representação social do "bom" professor de educação infantil (Fernandes);

- representações sobre "fala e escuta na sala de aula" (Farias);

- representações sobre sexualidade na escola (Flores; Coutinho);

- representações de professores sobre a luta pela terra em região de assentamento rural (Rocha);

- representações de professores em formação inicial sobre a Matemática (Barbosa da Silva);

- representações de professores de Matemática sobre o aluno da escola pública (Ramos da Silva);

- representações sobre violência no ambiente escolar (Batista da Silva; Bianchi);

- representações sobre o conceito de conscientização presente nas apropriações das concepções pedagógicas de Paulo Freire (Alimandro);

- representações sociais dos professores sobre pré-adolescentes (Delalibera);

- representações sociais de gênero das professoras sobre o magistério (Santos);

- relação entre as representações sociais dos professores sobre o processo de ensino-aprendizagem e a informática na educação (Calvacanti);

I. Ver Relação das Teses e Dissertações analisadas no final do artigo. 
- representações de professores de História sobre a educação patrimonial e patrimônio (Amorim);

- representações de professores sobre o que pensam seus alunos da perspectiva de futuro (Pizaneschi);

- representações dos professores sobre a escola no presente, no passado e no futuro (Albuquerque Silva);

- representações de professores sobre meio ambiente, educação ambiental e suas relações com a prática docente (Ferreira);

- representações de professores sobre o corpo humano e suas repercussões na prática pedagógica (Shimamoto).

Uma das primeiras perguntas que fizemos ao analisar os trabalhos foi se o objeto escolhido, dentro do tema proposto, constitui, de fato, um objeto de representação para os sujeitos da pesquisa. Como diz Sá (1998), frequentemente aquilo que o pesquisador considera como objeto relevante de pesquisa ou objeto de representação social pode ser para ele, mas não para os sujeitos. Moscovici, por sua vez, sustenta desde o início de suas investigações, em 1961, que um objeto de representação social é, necessariamente, um objeto de relevância ou "força" social para um grupo de sujeitos, de modo a provocar a construção das representações em torno de si, e isso não ocorre com qualquer objeto (Moscovici, 1978).

Assim, analisamos nos trabalhos a escolha dos objetos de representações sociais e questionamos se as variáveis definidoras do grupo de sujeitos dão conta do objeto escolhido para investigação, e ainda se há uma construção teórica do objeto.

Constatamos que, na maioria dos casos, trata-se de objetos de representação para os sujeitos da pesquisa. "Identidade do professor", "avaliação", "curso de Pedagogia", "sexualidade", "luta pela terra", "função do professor e da instituição de educação infantil", "formação inicial sobre a Matemática", "violência no ambiente escolar", "concepções pedagógicas de Paulo Freire", "pré-adolescentes", "gênero e magistério", "informática na educação", "profissão e profissionalização", "educação patrimonial”, "escola do passado, presente e futuro", "meio ambiente e educação ambiental" e "bom professor" são, sem dúvida, objetos que levam a representações homogêneas, comuns aos grupos investigados. 
Além disso, grande parte dos trabalhos busca fazer uma construção teórica do objeto, retomando, investigando como ele se constituiu historicamente. É o que vemos, por exemplo, no trabalho de Cunha, que procura descrever como se construiu a avaliação na Educação Física, partindo das origens dessa disciplina e de sua tradição mais biologizante, técnica, até chegar à configuração atual como "cultura do movimento".

Outro estudo ilustrativo nesse sentido é o de Santos. Essa autora, ao estabelecer uma articulação entre gênero, magistério e representação social, aborda a constituição histórico-social da categoria de gênero, de forma geral, e, posteriormente, na educação, enfocando o processo de feminização do magistério com a entrada e permanência das mulheres no sistema educacional, e a produção da feminização desse campo profissional, relacionada com os aspectos simbólicos e subjetivos dessa realidade.

Cavalcanti revela a mesma preocupação ao apresentar o contexto social que impulsiona a mudança de paradigmas no sistema educacional. Examina as repercussões da inserção da informática na educação e relaciona as mudanças na área com a ação pedagógica do professor na construção do processo ensino-aprendizagem.

Embora as teses e dissertações analisadas, em sua maioria, façam uma recuperação histórica e contextual dos objetos das representações que pretendem estudar, dificilmente averiguam as transformações históricas dessas representações nos grupos investigados. É como se a TRS servisse sobretudo para a coleta de dados sobre a representação do objeto em um momento posterior da pesquisa, mas não esclarecesse sobre sua natureza, origem, construção ou transformação.

Há, porém, algumas exceções. Rocha, por exemplo, se preocupou com uma reconstrução histórica do sentido da posse da terra e da escola rural para o grupo pesquisado de maneira a construir o objeto utilizando a TRS como base de uma problematização consistente e adequada. David demonstra que as representações sociais de uma creche específica estão diretamente relacionadas às condições sociais, históricas e materiais das práticas das participantes da pesquisa, uma vez que foram protagonistas da história de sua fundação. As representações de creche e de professor de creche são partilhadas pelas participantes e Ihes dão um sentimento de pertencimento ao grupo que lutou pela melhoria da vida das pessoas da comunidade da qual 
faziam parte, o que teve um efeito positivo na construção de suas identidade. A autora focaliza também a mudança das representações, demonstrando que, ao não serem mais responsáveis pela manutenção da creche, no momento em que as condições sociais, históricas e materiais das práticas se modificam, o modo de apropriação destas por parte do grupo também se altera: "Eles não são mais protagonistas de sua história", diz David. Assim, o sentido de ser professor, nesse caso, varia em função do sentimento de pertencimento ao grupo e do tempo vivido.

\section{Os sujeitos das investigações}

Representações são sempre de alguém e sobre algo, como diz Jodelet (1986). E, como construções simbólicas, carregam as características de quem as faz. Os trabalhos analisados centram-se em representações de ou sobre professores e tiveram como sujeitos, em sua maioria, docentes em exercício ou alunos em formação para o magistério de várias localidades do país.

Grande parte dos trabalhos caracteriza razoavelmente os sujeitos de investigação: são fornecidas informações sobre idade, gênero, série em que atuam, tempo de magistério, tipo de escola, tipo de função etc. Com base nesses dados, verifica-se que a faixa etária dos professores é bastante variada, assim como o tempo de magistério. O gênero é predominantemente feminino, quando não exclusivamente, o que, de um lado, indica a escassez de trabalhos com professores do sexo masculino, e, de outro, a prevalência de mulheres especialmente na educação infantil e no ensino fundamental. As escolas em que atuam são, na maioria, públicas, da rede municipal ou estadual, e uma parcela importante dos professores é formada, ou está em vias de formação, em Pedagogia, Normal Superior ou outro curso de nível superior.

Entretanto, faltam dados que caracterizem melhor os sujeitos como grupo constituinte de representações sociais. Em quase todos os trabalhos, o simples fato de os sujeitos terem em comum a profissão de professor parece ser considerado como condição suficiente para pertencer a um mesmo grupo de representação. Dificilmente há investigação a respeito de outras variáveis que liguem os sujeitos entre si. Faltam ainda informações que descrevam o contexto cultural e histórico em que o grupo se constitui ou o que marca os sujeitos em sua pertinência àquele grupo. 
Outro problema é que os autores quase nunca revelam as razões que os levaram à escolha dos sujeitos de estudo, e são poucas as pesquisas comparativas que trabalham com representações de diferentes grupos sobre o mesmo objeto, embora muitas delas componham seus universos com variáveis diversas.

Vale destacar, no entanto, que alguns trabalhos se preocupam em compor amostras estatisticamente representativa da população. Por exemplo, os trabalhos de Pizaneschi, de Albuquerque Silva, de Coutinho e de Bianchi.

O tamanho das amostras é bastante variável: em oito pesquisas, elas eram formadas por até 20 sujeitos; em cinco pesquisas, por mais de 20 e menos de 40; em oito, por mais de 40 e menos de 100; em três, por mais de 100 e menos de 200; em duas, por mais de 200; e um trabalho não especificou o número de sujeitos.

Cavalcanti chama a atenção para um problema importante: a dificuldade de conseguir a participação dos professores nas pesquisas. Relata que alguns de seus sujeitos expressaram que "os pesquisadores só criticam e não contribuem".

Diante dessa resistência, indagamos se as investigações com professores e, mais especificamente, na área das representações sociais e educação, têm retornado seus resultados aos sujeitos pesquisados e às suas instituições. E se há um trabalho de pesquisas-ação em nível de intervenção ou de propostas para a mudança de representações e práticas sociais. Entre as teses e dissertações analisadas no presente trabalho, nenhuma delas adota esse tipo de metodologia, e poucas se voltam aos processos de transformação das representações e práticas sociais.

\section{Revisão bibliográfica}

É de praxe nas teses e dissertações analisadas um bom capítulo apresentando a TRS. Quase todas elas situam a origem dos conceitos básicos da teoria nos estudos de Moscovici (1978) sobre as representações sociais da psicanálise. Procuramos seguir o movimento desse capítulo nas teses e dissertações investigando as fontes e autores citados, se havia coerência entre eles, se as fontes eram primárias ou secundárias, se eram atuais, se autores brasileiros eram usados e se havia uma revisão de estudos sobre o tema investigado.

Constatamos que a maioria dos capítulos de revisão teórica segue um mesmo movimento, definindo os conceitos principais da teoria: representação 
como construção simbólica, representação como social, ancoragem, objetivação, análise processual, análise estrutural. Os trabalhos de Moscovici (1978, 1984, 1995, 2001, 2003) são citados em 25 das 27 teses e dissertações analisadas; os de Jodelet (1989, 1994, 1999, 200 I), em 21; os de Abric (1994, 1998, 2000) em 14; os de Gilly (1984, 1994, 200 I) em oito; e os Doise (1990, 1992, 1998) em cinco. Há autores brasileiros bastante citados como: Sá (1995, 1996, 1998), em 16 trabalhos; Alves-Mazzotti (1994, 1996, 1998, 200 I, 2002), em I 5; Madeira (199I, I997, 2000, 200 I), em I 2; Spink ( 1995), em sete; e Guareschi e Jovchelovitch (1995), em seis. Não há confrontos entre os autores, uma vez que cada conceito é descrito separadamente. Na maioria dos trabalhos são utilizadas fontes primárias de referência.

Contudo, sentimos falta de uma revisão de estudos e pesquisas já realizados em representação social sobre os temas ou objetos investigados. Pela quantidade de trabalhos produzidos no Brasil e publicados em anais de congressos, livros e periódicos, podemos dizer que sua consulta e citação em teses e dissertações deixa a desejar. E mesmo nos trabalhos que têm o cuidado de fazer essa revisão, ela é pouco utilizada para discutir os resultados obtidos.

Verificamos também, e vamos voltar a esse ponto mais adiante, que embora o capítulo de revisão da teoria seja muitas vezes bem completo, ele tende a ser "esquecido" no decorrer dos trabalhos, ou apenas uma parte muito pequena dos conceitos descritos é retomada na análise e interpretação dos dados.

\section{Procedimentos de coleta e tratamento dos dados}

Os procedimentos de coleta de dados mais usados nos trabalhos com ou sobre professores foram entrevistas (em 22 teses e dissertações), seguidos de questionários (em 16) e, dentro deles, as questões de associações livres, adotadas em II estudos, com palavras indutoras em temas como: avaliação, ser professor, curso de Pedagogia, alunos de assentamentos, Matemática, violência, ensino, aprendizagem e informática. A observação foi empregada em seis estudos, os grupos focais em cinco e a análise documental em dois.

Vários estudos combinam mais de um procedimento de coleta, como os de Marujo, de Fernandes, de Costa e Silva e de Alimandro, que utilizam questionário e entrevista, os de Barbosa da Silva, de Flores e de Santos, que 
utilizam entrevista, questionário e observação, e os de Rocha e de Farias, que associam entrevista e observação.

Entretanto, poucos trabalhos têm a preocupação de justificar a escolha metodológica em função da TRS e das possibilidades de análise de dados que ela oferece, como faz a pesquisa de Shimamoto. Nesse estudo, para o acesso do conteúdo das representações sociais dos professores sobre o corpo humano, foi utilizado o teste de Associação Livre de Palavras com tratamento estatístico para a identificação de classes semânticas em função da ocorrência e da não-ocorrência das palavras e de seu agrupamento em um sistema temático. Com o intuito de alcançar a estrutura da representação, ou seja, seus elementos centrais, intermediários e periféricos, a autora empregou o método de Triagens Hierarquizadas Sucessivas, acompanhado da técnica do Quadro de Quatro Casas, de Vergès (1992). Além desse procedimento, Shimamoto utilizou uma entrevista semiestruturada para compreender o processo de produção da representação social de corpo pelos professores participantes e sua repercussão no ensino de Ciências.

Outro trabalho que tem o mesmo cuidado é o de Ramos da Silva, que também usou o teste de Associação Livre de Palavras, mapeando o campo semântico de maneira a identificar os elementos periféricos e nucleares da representação social do professor de Matemática sobre o aluno de escolas públicas e privadas. A autora utilizou a técnica de Construção de Planos Fatoriais de Correspondência entre as palavras expressadas pelos sujeitos e as variáveis de identificação, buscando circunscrever o núcleo das representações do professores.

A partir dos instrumentos mais usados, a entrevista e o questionário, constata-se que o tratamento de dados mais comum, quando as questões são abertas, é a busca de categorias de respostas por métodos mais qualitativos ou análises de conteúdo. Um dos autores mais citados, nesses casos, é Bardin (1977).

No total, I I teses e dissertações utilizam softwares para a análise dos dados. Por exemplo, a de Cavalcanti adotou o Trideux; as de Batista da Silva, de Rocha e de Bianchi, o Alceste; e a de Marujo, o Modalisa.

Nos estudos que empregam questionários com perguntas de evocação livre, bastante presentes, realizam-se análises estruturais, inspiradas em Abric (1994), em busca das respostas do núcleo central e das periféricas. No 
entanto, o método de contagem mais presente é o manual, com resultados apresentados em estatísticas simples de frequência. Poucos são os trabalhos que fazem cruzamentos desses dados de frequência com características diversas das populações estudadas, ou com análises estatísticas mais complexas.

Um trabalho que se destaca, nesse sentido, é o de Cavalcanti que, utilizando o Trideux, efetua uma análise fatorial de correspondências de variáveis. Primeiramente, faz um levantamento dos elementos constitutivos dos campos semânticos das RS sobre o ensino, a aprendizagem e a informática na educação e os categoriza. Em seguida, identifica os esquemas nuclear e periférico das representações sociais, por meio de análise fatorial de correspondência, com representação gráfica em planos fatoriais. Por fim, determina semelhanças e diferenças entre as representações conforme as palavras evocadas e as diversas características dos sujeitos.

Um aspecto importante destacado por Cavalcanti foi a diferença entre as representações dos professores sem experiência com informática daquelas dos professores com experiência. Enquanto para os primeiros a informática é vista apenas como uma ferramenta metodológica que propicia a renovação da prática pedagógica em razão do uso dos recursos educacionais, para os últimos a informática na educação é associada à dimensão afetiva como instrumento motivador do processo de construção do saber.

\section{A análise dos dados}

No estudo das dissertações e teses, questionamos os tipos de análises realizadas (categorial, de discursos, processual, estrutural ou outras); se elas foram feitas de modo consistente; se suas inferências foram adequadas; como utilizaram a TRS; e como consideraram as expressões dos sujeitos. As mais comuns são as análises de discurso, de conteúdo, temática, categorial e descritiva. Em sete estudos foram utilizadas análises estruturais.

Constatamos nos trabalhos certa dificuldade de realizar análises de dados com toda a riqueza que seria adequada a uma pesquisa de doutorado ou mestrado. Como dissemos, embora muitos trabalhos contenham um bom capítulo sobre a TRS, ele não volta a ser usado no momento da análise dos resultados, a não ser de forma bem limitada ou restrita; por exemplo, na constatação dos elementos centrais ou periféricos de uma representação. Dificilmente outros 
conceitos da teoria aparecem na análise, e ela resta subexplorada no desenrolar do trabalho.

Como já dissemos também, embora haja grande produção de trabalhos sobre representação social e educação, há poucas comparações dos dados obtidos nas teses e dissertações com pesquisas anteriores. Exceções são os trabalhos de Rocha, de Bianchi e de Coutinho.

Procurar explicar os dados obtidos acerca das representações sociais através da história da construção desse saber como senso comum e como ciência dá margem a muitos desdobramentos importantes, mas são poucos os trabalhos que têm essa preocupação. Alguns mostraram a correspondência dos resultados encontrados nas associações livres com a história da construção cultural desses conceitos, evidenciando, portanto, a ancoragem das representações em conteúdos antes tomados como científicos ou mesmo normativos para um campo do saber.

Cunha, por exemplo, identifica representações centrais de avaliação em Educação Física ligadas à saúde e à mensuração, e explica como essas ideias se relacionam a conceitos anteriores da disciplina relacionados à área da Saúde e, também, da competição esportiva.

Cavalcanti busca comparações entre o senso comum e teorias científicas, evidenciando o quanto as perspectivas pedagógicas tradicionais, construtivistas, behavioristas e sociointeracionistas influenciam a construção das representações sociais das participantes sobre ensino e aprendizagem e as relações dessas com as representações sociais sobre a informática na educação. A autora procura responder à origem dessas representações com base também no contexto de inserção dos participantes e na realidade educacional brasileira, no que diz respeito à informatização.

No caso da pesquisa de Ferreira, as representações de meio ambiente e educação ambiental são situadas no âmbito das concepções científicas de ciência e natureza construídas ao longo da história; o autor analisa como os princípios da racionalidade técnica têm determinado as formas de relação dos seres humanos com o meio ambiente no mundo moderno, prevalecendo uma visão utilitarista da natureza. Embora já esteja em curso um debate voltado à construção de uma racionalidade inserida em um discurso pós-moderno, que considera os fatores macrodeterminantes nas formas de relação dos seres humanos com o meio ambiente, esse aspecto relacional esteve muito pouco 
presente nos discursos dos professores participantes da pesquisa. A maioria deles não abordou a questão ambiental como associada a fatores políticos, econômicos, culturais, sociais e históricos.

\section{Resultados destacados nos estudos analisados}

Procuramos verificar nos resultados das teses e dissertações a que conclusões chegam os autores e quais as principais contribuições dos estudos para a TRS, para a educação e para o conhecimento do tema específico: as representações sociais de e sobre o professor.

Constata-se que os estudos oferecem contribuições mais relevantes para a educação, no que se refere especificamente ao professor e seu contexto de vida profissional, do que para a TRS. Consideramos isso uma decorrência do fato de que os trabalhos analisados são, em sua maioria, dissertações de mestrado desenvolvidas em prazos de dois a três anos, tempo insuficiente para reflexões teórico-epistemológicas mais aprofundadas.

Centrando-nos nas contribuições das pesquisas sobre as representações de ou sobre o professor e seu contexto de vida profissional, tratamos de reunir seus resultados em grandes categorias de forma a verificar o que revelam sobre as representações comuns - mais frequentes e/ou repetidas - desse profissional sobre: sua profissão (profissionalização, o "ser professor", a sua "identidade"); a instituição em que trabalha (creche ou escola); os processos formativos (formação inicial e continuada); os processos pedagógicos e relacionais de seu trabalho na escola; seus alunos.

Adiantamos que pudemos traçar apenas algumas generalizações dentro dessas categorias, dada a grande diversidade de temas dos 27 trabalhos analisados. No entanto, elas são suficientes para mostrar que a TRS, mesmo utilizada de modo limitado, é um instrumento poderoso para sugerir imagens sobre como o professor estrutura seu mundo profissional.

No que diz respeito à instituição em que o professor trabalha, as pesquisas de Albuquerque Silva sobre a escola no presente, no passado e no futuro, e de David, sobre uma creche comunitária revelam em comum uma visão muito mais positiva da instituição no passado do que atualmente.

Na primeira, a escola do passado é vista como boa, lugar de estudos e aprendizagem dos alunos e onde a família está presente; a escola de hoje é 
carregada de negatividade, de má qualidade de ensino e ausência da família; a escola do futuro é representada em torno da objetivação de informatização e estrutura física.

A pesquisa de David mostra que a visão positiva do passado dos antigos profissionais de uma creche está ligada a um sentimento de pertencimento ao grupo fundador da instituição, e que transformações das representações sobre a creche ocorrem em razão das transformações da própria creche após a intervenção do poder público e de suas formas de administração: contratação de professores concursados, de fora da comunidade, com formação técnica mais reconhecida oficialmente e afastamento dos antigos profissionais fundadores da instituição, vistos como "profissionais de segunda categoria".

Se na pesquisa de Albuquerque Silva as representações positivas da escola de antes decorrem da idealização do passado diante das dificuldades do presente, na de David essas representações ancoram-se no sentimento de responsabilidade em relação à própria instituição e à comunidade na qual o profissional e a instituição estão inseridos, fazendo parte de uma mesma história e memória.

Das pesquisas que contribuíram para revelar o que professores pensam acerca de sua formação, destacam-se as de Alimandro sobre concepções pedagógicas de Paulo Freire e as dimensões políticas da formação de professores e a de Costa sobre o ingresso de professores na formação continuada e seus reflexos em suas práticas.

Alimandro verificou que a maioria dos professores não participa de atividades sindicais e que nem todos percebem claramente a função política da educação, mesmo quando afirmam que procuram direcionar os alunos a um processo de compreensão da realidade e de formação do pensamento crítico.

Costa, por sua vez, constatou que os professores, ao refletirem criticamente sobre sua formação continuada, acreditam que as mudanças na prática docente ocorrem em quatro domínios: nova representação do lúdico; nova visão de aluno; novo olhar sobre o saber docente; e novo sentido à escrita e ao processo de alfabetização. As representações sociais do ingresso na formação continuada podem ser reconstruídas ao longo do processo formativo e incidem positivamente na modificação das representações sociais de trabalho pedagógico e no processo de construção de uma nova identidade profissional.

Nos trabalhos que investigaram os processos pedagógicos e relacionais, a maioria revela o quanto as representações sociais dos professores repercutem 
na forma de apropriação dos conteúdos ministrados na escola, e sugere que essas representações podem direcionar a prática pedagógica docente. Essas pesquisas indicam ainda a necessidade de os cursos de formação de professores considerarem suas representações e fundamentarem seus programas com base nelas, uma vez que são reveladoras dos saberes construídos pelos professores e que supostamente orientam seu fazer cotidiano no espaço escolar. Destacam-se nessa linhas os trabalhos de Amorim, de Cavalcanti, de Ferreira e de Shimamoto.

Amorim, ao investigar as representações de professores de História sobre educação patrimonial e patrimônio, indica que apesar de estarem em sintonia com os documentos oficiais, como, por exemplo, os Parâmetros Curriculares Nacionais, os docentes ainda entendem o termo patrimônio dentro de uma concepção tradicionalista e apresentam uma visão romântica de sua disciplina. O autor adverte para a necessidade de formações que favoreçam a apropriação de novos conhecimentos produzidos pelas pesquisas sobre o ensino de história para a condução de novas práticas.

Ferreira estuda as representações de meio ambiente e educação ambiental de professores e como elas se relacionam com a prática em sala de aula. Segundo a autora, predomina entre eles uma visão simplista e ingênua, que não leva em consideração os macrodeterminantes nas formas de relação dos seres humanos com o meio ambiente. Ela enfatiza que o debate em torno da questão ambiental depende mais das representações dos professores sobre meio ambiente e educação ambiental do que da existência de disciplinas específicas, uma vez que esse tema deveria ser focalizado nos mais diversos espaços escolares. Salvo exceções, as disciplinas específicas não têm contribuído significativamente para a efetivação da educação ambiental na escola. Na verdade, elas podem até mesmo funcionar como mais uma forma de fragmentação, contrariando a proposta de meio ambiente como tema transversal e como discussão não-disciplinar, integrada e complexa. Não há, segundo a autora, carência de produção e discussão sobre o meio ambiente. $\bigcirc$ que é urgente é a democratização do que se produz e a ampliação do debate no âmbito da formação de professor, da escola e da sociedade.

Cavalcanti pesquisou em que medida as representações sociais dos professores sobre ensino-aprendizagem interferem na construção de suas representações sobre a informática na educação. Ele chegou a dois tipos de 
representações sobre o processo ensino-aprendizagem que influenciam as representações dos professores sobre a informática: no primeiro, baseado na concepção tradicional, o computador é visto apenas como um recurso, como uma ferramenta útil para o treino de capacidades e habilidades; no segundo, baseado em uma concepção pedagógica voltada ao construtivismo, os recursos computacionais são vistos como um dispositivo eficaz para a construção de novas situações de ensino e aprendizagem significativas tanto para o aluno como para o professor. A autora ressalta a necessidade de a formação de professores proporcionar uma postura reflexiva de atuação, fundamentada em concepções atuais sobre o processo de ensino-aprendizagem e a mediação do uso da informática na educação.

Shimamoto analisa as representações sociais de professores sobre o corpo humano e suas repercussões na prática pedagógica. Ela constata que essas representações estruturam-se em torno de um núcleo central que destaca elementos de natureza biológica, coloridos de matizes periféricos de naturezas sociais, culturais, afetivos e psicológicos. Os resultados, segundo ela, mostram a necessidade de repensar o ensino do corpo humano na aula de Ciências Naturais. Como expressão da natureza humana, o corpo deve ser considerado em uma perspectiva holística, como um grande sistema de interação. $\bigcirc$ professor precisa ter uma consciência crítica de suas próprias representações, sob pena de colaborar para a construção de uma concepção de corpo humano fragmentado e dissociado de si, dos outros e do mundo.

As pesquisas que têm como objeto de estudo as representações dos professores a respeito de seus alunos, ligadas a temas e contextos específicos, procuram identificar como essas representações podem estar ancoradas nas experiências cotidianas, em modelos sociais vigentes ou no conhecimento científico, e a possível influência dessas representações na relação do professor com seus alunos e na prática pedagógica.

Coutinho, por exemplo, ao tratar das representações da sexualidade de alunos de escolas públicas pelos professores, mostra que elas estão ancoradas em modelos tradicionais que continuam sendo repassados pela sociedade. Os resultados indicam que os professores se sentem mal preparados para abordar o assunto sexualidade na escola, coincidindo com o que os alunos pensam a respeito. Eles acreditam que há diferenças entre o que alunos da quinta série e da oitava pensam e buscam saber sobre sexualidade, que os alunos têm poucas 
fontes de informação sobre o assunto, que os meninos têm representações diferentes das meninas, e que os alunos têm pouco compromisso educacional com a escola.

Delalibera investigou as representações sociais dos professores sobre os pré-adolescentes e a forma como elas podem repercutir nas relações professor/aluno no contexto da instituição escolar. Os resultados indicam que os pré-adolescentes são vistos pelos professores como um grupo heterogêneo, caracterizado pela diversidade tanto cognitiva, como afetiva e psicossocial, e definidos como "nem crianças, nem adolescentes". Essas representações, segundo a autora, geram incertezas e contradições nos professores e interferem na relação professor-aluno e na prática pedagógica. Para ela, a compreensão da pré-adolescência pode ser facilitadora das relações na escola.

Ramos da Silva, ao pesquisar as representações do professor de Matemática sobre o aluno de escola pública, identificou que há diferenças entre o que os professores pensam sobre esse aluno e o de escola particular em relação à Matemática: eles veem os primeiros com um olhar negativo, consideram que eles têm poucas chances de aprender Matemática.

Rocha estudou as representações de professores sobre alunos oriundos de assentamentos, observando que aqueles que têm vínculos pessoais com proprietários de terra apresentam mais dificuldade de reelaborar suas representações sociais sobre esses alunos e, inversamente, aqueles que têm vínculos com os assentados acabam por idealizar ao extremo seus alunos. $\bigcirc$ autor conclui pela necessidade de repensar os limites das dicotomias idealizar/ depreciar, rural/urbano, emoção/cognição, teoria/prática, conteúdo/processo, na formação do professor que lida com essa nova realidade brasileira.

Das 27 pesquisas analisadas, oito delas (Sixel da Silva; Costa e Silva; Marujo; Brito; David; Assis; Santos; Fernandes) tratam de representações sociais de professores em diferentes níveis de escolaridade sobre o ser professor e sua identidade profissional, contribuindo para uma melhor compreensão dessa temática.

Costa e Silva, por exemplo, ao estudar as representações de identidade profissional docente, conclui que existe uma crise na elaboração da identidade do professor, oriunda do momento histórico e cultural que concebe um novo modo de "ser" e de "estar" na profissão docente, bem como da ancoragem de representações sociais de uma identidade docente própria desse mesmo 
momento. Porém, para o autor, o que marca definitivamente a identidade docente "é que ser professor é lidar com humanos que necessitam 'se hominizar". Marujo, por sua vez, conclui que os professores veem a docência como uma profissão cujo modelo se aproxima do "modelo de traços". A autora estabelece uma distinção entre profissionalidade (processo interno de profissionalização) e profissionismo (processo externo de profissionalização). Os professores associam a profissionalidade aos conhecimentos (conteúdos) e saberes de experiência que o docente precisa utilizar na sua atividade e o profissionismo às lutas que o professor precisa travar pela valorização da profissão.

David, que estudou professores de creches, mostra que o sentido de ser professor varia em função do sentimento de pertencimento ao grupo e do tempo vivido. O passado é entendido como um período de valorização, de luta e conquistas, de autonomia e de superioridade em relação ao presente, que é associado a termos como desvalorização, cansaço, falta de cumplicidade e desestímulo. A autora indica que há um agravante em se tratando de professores de educação infantil, que se veem desvalorizados pela comunidade, pela própria categoria profissional e pelos órgãos públicos, como a Secretaria de Educação, que os trata como profissionais de "segunda categoria" ou "babás". Como forma de combater o sentimento de "rejeição" diante de um grupo profissional e de sentir-se valorizado, o professor da educação infantil acaba negando a afetividade e exclui o conceito do "cuidar" e de "maternagem" de sua identidade profissional, distanciando-se com isso de seus pequenos alunos. $O$ trabalho sugere que os vínculos mantidos com a comunidade contribuem para o fortalecimento das relações entre escola e família e para uma identidade positiva do professor.

Brito mostra que os professores em processo de formação em serviço passam por inúmeras dificuldades que tornam o exercício profissional autônomo complicado, mas que, mesmo diante das adversidades, esses docentes conseguem criar estratégias de atuação e têm condições de contribuir para o desenvolvimento dos saberes necessários ao exercício de sua profissão. $\bigcirc$ autor mostra que esses profissionais possuem um saber que precisa ser valorizado. $E$ adverte que os cursos de formação em serviço não devem destituí-los de seu saber "ser professor", mas sim possibilitar que contribuam de forma mais ativa com esse saber para o desenvolvimento de sua atuação profissional.

Santos chega à conclusão que as representações sociais de gênero sobre o magistério partem do sentido atribuído ao ser mulher, ao magistério e ao ser 
professora. O magistério é representado como um campo socioprofissional importante, difícil e desvalorizado, cujas exigências vão além da questão de gênero, embora esta esteja presente nas falas das participantes da pesquisa. A desvalorização das professoras, segundo elas, não é determinada pelo fato de o magistério ser constituído predominantemente por mulheres, mas sobretudo pela realidade social e econômica e pela qualidade da política educacional, especialmente para os anos iniciais do ensino fundamental. Esse estudo revela assim as construções individuais-sociais dos próprios sujeitos envolvidos no magistério, apontando para as dificuldades enfrentadas na profissão, as realizações e propósitos profissionais, com o foco na questão de gênero. Ressalta ainda a importância das discussões de gênero no processo de formação inicial e continuada dos professores e professoras.

Um último trabalho que incluímos no conjunto sobre o "ser professor" é o de Fernandes. Estudando as representações sociais do "bom" professor de educação infantil em alunas de primeiro ano e de último ano do curso de Pedagogia, Fernandes encontrou duas visões aparentemente distintas: enquanto as alunas do primeiro ano representam o professor como um animador, portanto de forma pessoal, as do último ano o representam como um mediador, incorporando uma categoria acadêmica. Entretanto, como a noção de mediação é muito abstrata, percebe-se que perdura a concepção de professor animador nas alunas do último ano. Assim, elas incorporam apenas parcialmente as categorias acadêmicas às representações sociais de bom professor. Essa incorporação permanece no nível do discurso: o professor deve ser um mediador, mas não ficam claros o objeto e o objetivo da mediação.

As pesquisas analisadas mostram que a valorização (ou a desvalorização) do professor parece ser uma preocupação constante desses profissionais. Indicam também que os cursos de formação inicial ou continuada precisam considerar esses aspectos e contemplar em seus currículos conhecimentos teóricos e práticos que permitam ao docente um fazer seguro e legitimado como fundamental para o desenvolvimento da sociedade. Em suma, parece-nos que todos os trabalhos analisados se preocupam em apontar para uma representação do profissional professor como desvalorizado e que precisa de uma atenção especial tanto nas políticas quanto nas práticas pedagógicas e formativas. 


\section{CONCLUSÕES}

As análises que fizemos possibilitaram um olhar crítico sobre as dissertações e teses. Ele apontou certas ausências e deficiências na utilização da TRS como referência teórico-metodológica. Numa palavra, a teoria é subutilizada nas pesquisas, fornecendo um ou outro instrumento de investigação ou de análise que permanece invariavelmente separado do restante do trabalho. Aparece mais como ferramenta para escolha de procedimento de coleta de dados ou de análise de um aspecto do objeto de estudo do que como corpo teórico inspirador de hipóteses ou de análises.

No entanto, encontramos pontos positivos nos trabalhos:

- houve pertinência e relevância nos objetos de investigação das teses e dissertações no campo da formação de professores - os vários temas de representações dos professores - mesmo que esses objetos não tenham sido estudados pela TRS com todos os seus recursos;

- o mesmo se pode falar da escolha dos sujeitos participantes das pesquisas e da constituição de grupos que, por vezes, levou à identificação de subgrupos;

- em geral, houve uma contextualização histórica dos objetos de representação estudados, mesmo que algumas vezes ela não tenha sido retomada na interpretação dos dados;

- constata-se a utilização de procedimentos de coleta de dados mistos e de combinação de formas de coleta de dados por vezes bem criativa; isso acontece mesmo que as análises dos dados ainda tendam a uma certa superficialidade, seja em termos de recursos que poderiam ter sido incorporados, seja em termos do aprofundamento das questões que seria possível com um melhor aproveitamento da TRS;

- sobre esse último ponto, consideramos ainda que os trabalhos sobre representação social são predominantemente descritivos (ver Menin; Shimizu, 2005) deixando de explorar as potencialidades explicativas que a teoria tem em relação a vários de seus conceitos, tais como: a origem e história de construção das representações, os processos de ancoragem e objetivação, as propriedades estruturais, as funções de simbolização e as sociais, os papéis dos meios de divulgação, a 
importância das comparações entre grupos de sujeitos, a relevância das comparações entre diferentes formas de conhecimento, a origem das transformações nas representações, as possíveis correspondências entre representações e práticas e outros pontos conceituais.

Finalmente, após analisarmos os trabalhos sobre representações de ou sobre professores, como podemos responder à questão de Denise Jodelet sobre os conhecimentos que a TRS tem trazido sobre o profissional professor no Brasil? Pensamos que há muitos resultados de diferentes qualidades, naturezas, realidades, obtidos com diferentes meios, sujeitos, temas. Só os 27 estudos que analisamos já nos trouxeram alguns bem interessantes.

Acreditamos que esse trabalho deve continuar. Nos últimos anos, novos avanços aconteceram no campo de pesquisas em representações sociais e nas técnicas de análises de dados. Além disso, a produção de trabalhos na área da educação continua aumentando. Uma análise mais direcionada para temas específicos, como por exemplo: uma seleção de todos os trabalhos de certo ano que estudem as representações que professores têm sobre o seu próprio trabalho ou sobre seus alunos ou sobre a sua formação, permitiria demonstrar se podemos construir um perfil do profissional professor através das suas representações reveladas por esses trabalhos.

\section{REFERÊNCIAS BIBLIOGRÁFICAS}

ABRIC, J. C. A Abordagem estrutural das representações sociais. In: MOREIRA, A. S.; OLIVIERA, D. C. (orgs.) Estudos interdisciplinares de respresentação social. Goiânia: AB, 1998. p.27-38.

A Abordagem estrutural das representações sociais. In: MOREIRA, A. S.

P.; OLIVEIRA, D. C. (org.) Estudos interdisciplinares de representação social. 2. ed. Goiânia: AB, 2000. p.27-38.

. Pratiques sociales et représentations. Paris: Presses Universitaires de France, 1994.

ALVES-MAZZOTTI, A. J. O Debate atual sobre os paradigmas de pesquisa em educação. Cadernos de Pesquisa, São Paulo, v.96, n.96, p. I 5-23, 1996.

Relevância e aplicabilidade da pesquisa em educação. Cadernos de Pesquisa, São Paulo, n. I 13, p.39-50, jul. 2001. 
Repensando algumas questões sobre o trabalho infanto-juvenil. Revista Brasileira de Educação, Campinas, v. 19, p.87-98, 2002.

Representações sociais: aspectos teóricos e aplicações à Educação. Em Aberto, Brasília, ano 14, n.6I, p.60-78, jan./mar. 1994.

Trabalho infanto-juvenil: representações de meninos trabalhadores, seus pais, professores e empregadores. In: MOREIRA, A. S. P.; OLIVEIRA, D. C. (org.) Estudos interdisciplinares de representação social. I. ed. Goiânia: AB, 1998. p.285-302.

ARRUDA, A. Pesquisa em representações sociais: a produção em 2003. In: MENIN, M. S. S; SHIMIZU, A. M. (org) Experiência e representação social: questões teóricas e metodológicas. São Paulo: Casa do Psicólogo, 2005. p.59-92.

BARDIN, L. Análise de conteúdo. Lisboa: Edições 70, 1977.

DOISE, W. L'Ancrage dans lés étude sur lés représentations sociales. Bulletin de Psychologie, n.45, p.189-195, 1992.

Les Représentations sociales. In: GHIGLIONE, R.; BONNET, C; RICHARD, J. F. (orgs.) Traité de psychologie cognitive, 3: Cognition, représentation, communication. Paris: Dunod, 1990. p.23-34.

Social psychology and human rights. European Review, n. 6, p.349-355, 1998.

GILLY, M. As Representações sociais no campo da Educação. In: JODELET, D. (org.) As Representações sociais. Rio de Janeiro: Eduerj, 200 I . p.32I-34l.

Les Représentations sociales dans le champ éducatif . In: JODELET, D. (org.). Les représentations sociales. Paris: Presses Universitaires de France, 1994. p.363-386. (Sociologie d'Aujourd'hui)

Psicosociologia de la educación. In: MOSCOVICI, S. (org.) Psicologia social, 2. Barcelona: Paidós, 1984. p.601-626.

GUARESCHI, P. A.; JOVCHELOVITCH, S. (orgs.) Textos em representações sociais. Petrópolis: Vozes, 1995.

JODELET, D. Folies et représentations sociales. Paris: PUF, 1989.

. Os Processos psicossociais da exclusão. In: SAWAIA, B. As Artimanhas da exclusão. Petrópolis: Vozes, 1999.

La Representación social: fenómenos, concepto y teoria. In: MOSCOVICI, S. Psicologia social: pensamiento y vida social, 2. Barcelona: Paidos, 1986. p.469-494.

As Representações sociais. Rio de Janeiro: Eduerj, 2001. 
Représentations sociales: un domaine en expansion. In: JODELET, D. (org.) Les représentations sociales. 4 ed. Paris: Presses Universitaires de France, 1994. p.31-86. (Sociologie d'Aujourd'hui)

MADEIRA, M. C. Linguagem e representações sociais: quando a vivência se torna palavra. In: MADEIRA, M. C. (org.) Representações sociais e educação: algumas reflexões. Natal: EDUFRN, 1997. p.7-17.

Representações sociais e educação: importância teórico-metodológica de uma relação. In: MOREIRA, A. P. (org.) Representações sociais: teoria e prática. João Pessoa: UFPB, 200 I. p. I23-144.

Representações sociais: pressupostos e implicações. Revista Brasileira de Estudos Pedagógicos, Rio de Janeiro, v. 72, n. 171, p. I39-144, maio/ago. 199 I.

. Um aprender do viver: educação e representação social. In: MOREIRA, A. S. P.; OLIVEIRA, D. C. (org.) Estudos interdisciplinares de representação social. 2. ed. Goiânia: $A B, 2000$. p.239-250.

MENIN, M. S. S.; SHIMIZU, A. M. Educação e representação social: tendências de pesquisas na área - período de 2000 a 2003. In: MENIN, M. S. S.; SHIMIZU, A. M. (orgs) Experiência e representação social: questões teóricas e metodológicas. São Paulo: Casa do Psicólogo, 2005. p.93-130.

MOSCOVICl. S. Das representações coletivas às respresentações sociais: elementos para uma história. In: JODELET, D. (org.) As Representações sociais. Rio de Janeiro: Eduerj, 200 I . p.45-66.

Prefácio. In: GUARESCHI, P. A.; JOVCHELOVITCH, S. (org.) Textos em representações sociais. Petrópolis: Vozes, 1995. p.7-16.

Psychologie sociale, I. Paris: PUF, 1984. Introductión, p. 17-37.

A Representação social da psicanálise. Rio de Janeiro: Zahar, 1978.

Vozes, 2003.

Representações sociais: investigações em psicologia social. 2. ed. Petrópolis:

SÁ, C. P. A Construção do objeto de pesquisa em representações sociais. Rio de Janeiro: Eduerj, 1998.

Núcleo central das representações sociais. Petrópolis: Vozes, 1996.

Representações sociais: o conceito e o estado atual da teoria. In: SPINK, M.

J. (org.) O Conhecimento no cotidiano: as representações sociais na perspectiva da psicologia social. São Paulo: Brasiliense, 1995. p. 19-45. 
SOUSA, C. P. Estudos de representação social e educação. Psicologia da Educação, São Paulo, n. I4/15, p.285-324, 1\%/2 sem. 2002.

SPINK, M. J. (org.) O Conhecimento no cotidiano: as representações sociais na perspectiva da psicologia social. São Paulo: Brasiliense, 1995.

VERGÈS, P. L'Évocation de l'argent: une méthode pour la 'definition du noyau central de la représentation'. Bulletin de Psychologie, v. 45, n. 405, p.203-209, 1992.

WAGNER, W. Sócio-gênese e características das representações sociais. In: MOREIRA, A. S. P.; OLIVEIRA, D. C. (orgs.) Estudos interdisciplinares de representação social. I . ed. Goiânia: $A B, 1998$. p.3-25.

\section{Relação das teses e dissertações analisadas}

ALBUQUERQUE SILVA, I. de. A Linha do tempo e as representações sociais de professores do ensino fundamental acerca da escola em Cuiabá. Cuiabá, 2004. Dissert. (mestr.) Universidade Federal de Mato Grosso.

ALIMANDRO, M. G. E. A Apropriação das concepções pedagógicas de Paulo Freire por professores do ensino fundamental. Rio de Janeiro, 2004. Dissert. (mestr.) Universidade Estácio de Sá.

AMORIM, A. R. A. Educação patrimonial e patrimônio: as representações sociais do professor de história do ensino fundamental, da $5^{\mathrm{a}}$ a 8 a séries, das redes municipais do Recife e do Cabo de Santo Agostinho. Recif, 2004. Dissert. (mestr.) Universidade Federal de Pernambuco.

ASSIS, M. S. Representações de professoras: elementos para refletir sobre a função da instituição escolar e de professora de Educação Infantil. São Carlos, 2004. Dissert. (mestr.) Universidade Federal de São Carlos.

BARBOSA DA SILVA, E. B. O Impacto da formação nas representações sociais da matemática: o caso de graduandos do curso de pedagogia para início de escolarização.Brasília, 2004. Dissert. (mestr.) Universidade de Brasília.

BATISTA DA SILVA, J. A Escola enfrenta a violência: dos projetos às representações docentes. Presidente Prudente, 2004. Dissert. (mestr.) Universidade Estadual Paulista.

BIANCHI, K. S. A Violência e suas representações sociais: um estudo com professores de escolas públicas em Cuiabá. Cuiabá, 2004. Dissert. (mestr.) Universidade Federal de Mato Grosso.

BRITO, M. L. T. Saberes necessários ao professor: uma aproximação do conceito de autonomia e de suas implicações para o desenvolvimento da profissão docente. Salvador, 2004. Dissert. (mestr.) Universidade Federal da Bahia. 
CAVALCANTI, L. C. Ensino, aprendizagem e informática na educação: um estudo das representações sociais dos professores da educação básica. Recife, 2004. Dissert. (mestr.) Universidade Federal de Pernambuco.

COSTA E SILVA, L. R. Identidade profissional docente: as representações sociais dos alunos da Faculdade de Educação da Universidade Federal de Goiás. Goiânia, 2004. Dissert. (mestr.) Universidade Federal de Goiás.

COSTA, P. L. G. Representações sociais do ingresso na formação continuada e da ressignificação da prática docente. Natal, 2004. Dissert. (mestr.) Universidade Federal do Rio Grande do Norte.

COUTINHO, M. M. T. As Representações sociais que professores apresentam acerca do que avaliam ser as representações sociais de sexualidade de alunos do ensino fundamental de escolas públicas. Cuiabá, 2004. Dissert. (mestr.) Universidade Federal de Mato Grosso.

CUNHA, V. M. P. Repensando a avaliação: as RS compartilhadas pelos professores de educação física. São Paulo, 2004. Dissert. (mestr.) Pontifícia Universidade Católica de São Paulo.

DAVID, M. S. Histórias e memórias: representações sociais de creche por profissionais da educação infantil. Rio de Janeiro, 2004. Dissert. (mestr.) Universidade Estácio de Sá.

DELALIBERA, E. S. R. Representações sociais dos professores sobre os pré-adolescentes. Maringá, 2004. Dissert. (mestr.). Universidade Estadual de Maringá.

FARIAS, M. de L. S. O. Fala e escuta de professores (entre)laçam-se na sala de aula. São Paulo, 2004. Tese (dout.) Pontifícia Universidade Católica de São Paulo.

FERNANDES, M. Z. Representação social do bom professor de educação infantil. Itajaí, 2004. Dissert. (mestr.) Universidade do Vale do Itajaí.

FERREIRA, A. R. Meio ambiente: representações e práticas dos professores de ciências e biologia. Ponta Grossa, 2004. Dissert. (mestr.) Universidade Estadual de Ponta Grossa.

FLORES, A. M. P. Sexualidade: representações de professores do ensino médio. Santa Maria, 2004. Dissert. (mestr.) Universidade Federal de Santa Maria.

MARUJO, L. E. L. As Representações sociais sobre a profissão e profissionalização docente de professores(as). Natal. 2004. Dissert. (mestr.) Universidade Federal do Rio Grande do Norte.

PEREIRA, A. M. Curso de pedagogia: representações de alunos e ex-alunos sobre o curso e sua profissionalização - um estudo em Mato Grosso. São Paulo, 2004. Tese (dout.) Pontifícia Universidade Católica de São Paulo.

PIZANESCHI, E. Perspectiva de futuro e suas representações sociais um estudo com professores das escolas públicas de Cuiabá. Cuiabá, 2004. Dissert. (mestr.) Universidade Federal de Mato Grosso. 
RAMOS DA SILVA, M. I. Representações sociais do professor de matemática sobre o aluno da escola pública. Recife, 2004. Dissert. (mestr.) Universidade Federal de Pernambuco.

ROCHA, M. I. A. Representações sociais de professores sobre os alunos no contexto da luta pela terra. Belo Horizonte, 2004. Tese (dout.) Universidade Federal de Minas Gerais.

SANTOS, M. C. G. As Representações sociais de gênero das professoras sobre o magistério: feminização-feminilização do campo socioprofissional. Recife, 2004. Dissert. (mestr.) Universidade Federal de Pernambuco.

SHIMAMOTO, D. F. As Representações sociais dos professores sobre corpo humano e suas repercussões no ensino de ciências naturais. São Carlos, 2004. Tese (dout.) Universidade Federal de São Carlos.

SIXEL DA SILVA, L. M. S. Os Sentidos de "ser professor": o papel do curso normal superior. Petrópolis, 2004. Dissert. (mestr.) Universidade Católica de Petrópolis.

Recebido em: junho 2007

Aprovado para publicação em: setembro 2008 